\title{
The Use of Measurements in a Small City School System
}

\section{E. E. Keener}

To cite this article: E. E. Keener (1921) The Use of Measurements in a Small City School System, The Journal of Educational Research, 3:3, 201-206, DOI: 10.1080/00220671.1921.10879149

To link to this article: http://dx.doi.org/10.1080/00220671.1921.10879149

曲 Published online: 15 Dec 2014.

Submit your article to this journal $₫$

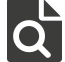

View related articles 
grant is not afforded an equal opportunity with the native child to become a good citizen.

When we examine the teachers, equipment, and building, we find scarcely a shadow of either equality or identity of opportunity, in comparison with the opportunity afforded by the better schools of today. In the latter the teachers are mature and well trained; and they employ much of the best material and most effective methods known to the educational world. The buildings are clean, well lighted, properly ventilated, and attractive; and the teaching equipment is modern and adequate. But in this village almost everything that goes to make up a modern school is lacking. Both building and equipment are wholly inadequate for obtaining the best results, and the majority of the teachers are immature and lack training. The pupils of this school are, therefore, clearly at a disadvantage with those of many other schools.

Although this village school is somewhat exceptional in regard to the mentality and nationality of its pupils, it is not unusual in other respects. It represents a common type found throughout the United States. The cause of such conditions is chargeable chiefly to one of our false notions of educational democracy, namely, the complete control of schools by local authorities. The remedy lies in the creation of a larger taxing unit; in adequate supervision by the county or state; in giving authority to the county superintendent (who must be free from political influence) to name or to nominate teachers; and in providing a central officer to condemn buildings and to prescribe modern types, without endangering his position through any sort of political chicanery. 


\title{
THE USE OF MEASUREMENTS IN A SMALL CITY SCHOOL SYSTEM
}

\author{
E. E. KeENER \\ Director, Educational Research, Richmond, Indiana
}

Up to the present time the measurement of the product of education, in most cases, has been left to the research student or to the school administrator. The results have been used either for writing theses on educational research, or for showing the superintendent or principal the condition of a school or class with reference to a set standard. The systematic use of standardized tests as a direct aid in teaching has been very limited. The classroom teacher has been unable to see the value of such measurements, not only because she knows little of the principle of measurements, but also because, as often happens, she does not even see the results of tests given to her pupils. Frequently, therefore, the teacher after scoring tests according to definite instructions, turns over the results to some one higher in authority without herself making any practical application of them.

Consequently many teachers have come to look on standard measurements as something which involves a great deal of extra work for themselves, and which seems to be of no practical value to anyone. Again, teachers who have had the meaning of scores explained to them, often raise the objection either that these scores do not give any additional information concerning the pupils or that they are so unreliable as to be of little value. Speakers at educational gatherings frequently emphasize the fact that it is useless to give tests unless something is done about them afterward; but they fail to say specifically what should be done.

In beginning the systematic use of measurements in any school system, the necessity for gaining the cooperation of the teachers is evident. With this in mind a department of measurements was established in the Richmond, Indiana public schools in the fall of 1919. The director of the work was also part-time principal of one of the grade buildings. The aim of the department was to make standard tests available for the classroom teacher, and to show her specifically how the results could aid in teaching. Since both educational and mental measurements were used (each as a supplement to the other), they will be discussed together. 
Testing was not forced on any school or on any teacher, but announcement was made that tests and information concerning them would be supplied when called for. At first there was little response. In the beginning therefore, the work was carried on chiefly at Baxter School over which the director had supervision. A group intelligence test was given to all the children in this school, and the Binet test was given to the very bright and to the very dull children. The Courtis Silent Reading Test and the Woody Arithmetic Scale, Series A, were also used in the proper grades.

The pupils who made high scores on both the intelligence and the educational tests were allowed to advance more rapidly than the normal rate of progress. Several did three half grades in one year. Those who were very dull were given, as nearly as possible, work suited to their ability. The ratings secured from these tests enabled the teachers to see each child as an individual problem and to aid him in overcoming his peculiar difficulties. "The greatest good to each pupil" thus becomes the slogan instead of "the greatest good to the group."

In the first three grades the pupils were grouped according to ability in the different subjects. Both the educational and the intelligence tests were used to make these groups as homogeneous as possible in ability. A pupil was sometimes in the highest group in reading and in the average group in arithmetic. The grouping was always kept flexible so that a child, whose improvement in any subject justified promotion, could be advanced to the next higher group. The brightest pupils were given more work than the average or slow pupils, and were often used as leaders for the slower pupils. A child of inferior ability was not expected to do average work. An effort was made to keep each child working up to the level of his capacity. In the upper grades the pupils of very low ability were sometimes excused from the less essential subjects like history and geography; and they were allowed to spend an extra amount of time on English, reading, writing, and arithmetic.

Long before this work in the Baxter School had been as thoroughly organized as has been described above, teachers and principals in other schools began to be heard from. They first asked that individual mental tests be given to those children who were especially poor in their work. When this request was complied with, some of these children were found to be subnormal; and 
others were found to be normal but lacking in push and determination. When the teachers learned the difficulty, they were enabled better to deal with each child as an individual problem.

Soon requests from the various schools for group mental and educational tests became so numerous that it was decided to extend the tests over the whole city, provided there was no serious objection among the principals or teachers. The intelligence tests used were the Pressey Primer Scale and the Pressey Cross-out tests. The educational tests were the Courtis Silent Reading Test and the Woody Arithmetic Scale.

In order to "sell" this work to the teachers, a meeting was held in each school building. The value of the tests as an aid in understanding the child as an individual problem and in grouping pupils according to ability was discussed. The diagnostic value of educational tests was stressed as of especial importance. The use of the results in comparing one class with another and with a standard was also emphasized. The limitations of existing tests as absolutely accurate means of measuring a child's ability at any one time without regard to temporary conditions was explained. The teachers were told to use caution in forming any definite and far-reaching conclusion from the results of any one or two tests. The results from all the tests, both educational and mental, combined with their own judgments and the opinions of superiors must be taken into consideration.

These suggested applications of the tests were carried out to some extent in all buildings, but by some teachers much more than by others. The attitude toward the principle of testing is highly gratifying. All teachers in the city, so far as I know, are now advocates of intelligence and educational ratings as an aid in fitting methods of instruction to the needs of pupils. This result of the first year's work alone was well worth the time and money which has been spent in establishing the system in the schools of Richmond. It paved the way for an organized and widespread system of procedure in 1920-1921.

During 1919-1920 group intelligence tests were given to practically all children from the first grade through the junior high school, and the Binet test was given to about 160 pupils. Most of the pupils who were given individual examinations were selected from those who were very poor in their work and who scored very low on the group test. Twenty-seven were found to have I. Q.'s 
of 69 or below. This means that the highest of this group will probably never develop beyond the mental level of eleven yearsi. e., beyond ability to do fifth- or sixth-grade work-in the same time that the normal child would finish high school. Thirty made a score of 70-79 I. Q., which means that the highest of this group will probably never rise above the mental level of normal children of twelve or thirteen years. There were many other pupils in the system who would have made similar scores, but who were not examined because of lack of time. There are without doubt some errors in these scores, but it is certain that a large majority of these pupils will never be able to do the regular school work, and that they will always be a serious problem in the classes. A special school should be established for these children where they can be taught the essentials in reading, arithmetic, writing, language, music, and hygiene. But much of their time should be spent in some kind of manual training which will prepare them better to meet life in the outside world and to become self supporting.

The Courtis Silent Reading Test was used in grades IIIB to VIA, and the Woody Arithmetic Scale in grades IVB to viris. ${ }^{1}$ In a number of classes these tests were given two or three times in order to measure improvement and the effect of special methods of teaching. Other tests were used in smaller numbers with various classes.

The application of test results may be illustrated by giving some specific instances in which tests were of special value to teachers and pupils. In one second grade the intelligence tests showed that the pupils ranged from moron to very superior in ability. They were arranged into groups as homogeneous as possible taking into account the results of the tests, the scholarship records, and the judgment of the teacher. The members of the slowest group learned much more rapidly when taken from the regular classes. One boy with an I. Q. of 52 had been in school for a number of years without being able to read at all. In a group where other children were not greatly superior to him, he learned to read easy material. Until this arrangement was made the teaching went entirely over his head. On the other hand, the brightest group did much more than the normal amount of work for the second grade. Six of the brightest pupils were put into the next higher grade, and their present success indicates that they will continue to advance at more than the normal rate.

${ }^{1}$ At Richmond, Section B is low and Section A high in each yearly grade. 
The Courtis Silent Reading Test was given to a very slow InIB class four times. It was given in October, January, March, and May. The score for the four tests was as indicated in the following table:

\begin{tabular}{l|r|r|r|r}
\hline \hline & \multicolumn{4}{|c}{ TesT } \\
\cline { 2 - 4 } & 1 & 2 & 3 & \multicolumn{1}{c}{4} \\
\hline Speed............. & 90 & 75 & 105 & 150 \\
Questions........ & 12 & 16 & 14 & 25 \\
Comprehension.... & 35 & 50 & 80 & 85 \\
& & & & \\
\hline
\end{tabular}

These results include only the scores of the children who were there for all four tests. After each test the class was divided into three groups: the first, below standard both in speed and comprehension; the second, below in speed only; the third, below in comprehension only. With this arrangement the teacher was able to give to each child the special work he needed. The class in June scored above standard in all points. This increase in ability could not have been accomplished by teaching the class as a whole, or by grouping the pupils without regard to their individual needs. The children of this class knew the standard score for their grade and whether their own score was above or below it. The fact that they knew this helped them to work more intelligently to overcome their own difficulties. The teacher of this class, though skeptical as to the value of tests at the beginning of the year, is now an enthusiastic advocate of them.

There are a number of instances where the tests were of special value to certain children. An over-age girl in the IA grade made a very high score in reading. She was skipped to the IIA grade and continued to do good work in reading. If her record is maintained she will be skipped again and work off her retardation.

A third-grade boy was unable to make any score on the Gray Oral Reading Test. Since he was suspected of being feebleminded, he was given the Binet test. This test showed him to be normal mentally; and accordingly further effort was made to find the cause of his poor reading. His eyes were tested with the letter chart and seemed normal. When questioned, however, he reported that the letters looked as if "someone had put a wet 